\title{
The Effects of Health Insurance on Health-Seeking Behaviour: Evidence from the Kingdom of Saudi Arabia
}

This article was published in the following Dove Press journal: Risk Management and Healthcare Policy

\author{
Mohammed Khaled \\ Al-Hanawi iD ' \\ Martin Limbikani Mwale ${ }^{2}$ \\ Tony Mwenda Kamninga (D) ${ }^{3}$ \\ 'Department of Health Services and \\ Hospital Administration, Faculty of \\ Economics and Administration, King \\ Abdulaziz University, Jeddah, Saudi \\ Arabia; ${ }^{2}$ Department of Economics, \\ Faculty of Economic and Management \\ Sciences, Stellenbosch University, Cape \\ Town, South Africa; ${ }^{3}$ Department of \\ Economics, Faculty of Social and Health \\ Sciences, Millennium University, Blantyre, \\ Malawi
}

Background: Saudi Arabia's healthcare sector is growing at a hasty stride; nevertheless, the quality of healthcare consumption remains challenged by the growing caseload in free public health facilities. Insurance could ease this pressure by moving some healthcare demand to private facilities conditional on its ability to enact health-seeking behaviour. These potential effects remain under-investigated. Therefore, the aim of this study was to investigate whether health insurance nudges health-seeking behaviour using data from Saudi Arabia.

Materials and Methods: The study used nationally representative secondary data, obtained from the Family Health Survey, conducted in 2018, in Saudi Arabia. Health-seeking behaviour was measured by individual attendance of medical check-up. To account for endogeneity due to non-random selection of individuals into insurance, the analysis employed the inverse propensity weighting and the instrumental variables methods.

Results: The results revealed that health insurance leads to increased chances of going for medical check-up. The effects are higher amongst non-Saudi nationals relative to citizens. Furthermore, people who purchase personal health insurance schemes are more likely to go for checks-ups, followed by individuals provided by the private sector and government sector. Finally, the study found that insurance positively nudges hypertension, diabetes, and cholesterol specific medical check-ups.

Conclusion: The findings indicated the need for health policy to increase access to health insurance in Saudi Arabia. A notable policy response is the introduction of national health insurance coverage, which has already proven in other countries as an effective measure to attain universal access to improved health. Nevertheless, results from this study highlighted variations in demand for health seeking based on type of insurance with highest returns in personal insurance. Policy should leverage on this behaviour response by introducing insurance packages that share premiums with citizens to incentivise utilisation. The results can also be used to design policy responses to demand for insurance, in the entire Arabian Gulf region, since these countries have similar health financing mechanism with Saudi Arabia.

Keywords: healthcare financing, health insurance, health sector, national health programs, Saudi Arabia

\section{Introduction}

Health insurance remains an imperative policy strategy for improving health outcomes at this crucial time, when many countries are pursuing the third Sustainable Development Goal (SDG) of safeguarding healthy lives and promoting well-being for all at all ages. ${ }^{1}$ Previous literature reveals that health insurance reduces the cost
Correspondence: Mohammed Khaled Al-Hanawi

Email mkalhanawi@kau.edu.sa 
of medication and hospitalization, which enables people to obtain better medical care during the treatment of various diseases. $^{2-4}$ Other studies, however, show that insurance does not significantly increase utilization of health services, especially in cases where the insured people would still obtain good medical care in the absence of the insurance. ${ }^{5}$ However, the effects work better where the insured are the marginalized. ${ }^{6}$ This strengthens the rationale for most countries establishing national health insurance schemes with an objective of assisting the poor to access good-quality healthcare.

Empirical evidence reveals that national coverage of insurance associates with a reduction in the burden of blood pressure in Nigeria. ${ }^{7}$ Furthermore, the scheme leads to reduced cancer mortality in the United States of America, ${ }^{8}$ and increases utilisation of community healthcare services amongst hypertensive and diabetes individuals in China. ${ }^{9}$ One of the observed transmission mechanism specific for diabetes reduction is the increased usage of insulin amongst the covered members. ${ }^{10}$ In addition, national health insurance is associated with improved births weights and newborn health status in Colombia. ${ }^{11}$

Despite a wide coverage of the effects of health insurance, the literature does not give adequate attention to variations in the effects based on insurance type. Moreover, little is known about the effects of insurance on health-seeking behaviour specifically that related to chronic disease medical check-ups. In addition, most of these studies do not establish causal evidence of the insurance on health outcomes.

The Kingdom of Saudi Arabia (KSA) is one of the countries in the process of extending insurance to the wider population, who, until present, have largely relied on free public healthcare, often engulfed with bottlenecks such as long waiting lines. ${ }^{12-14}$ Often some affluent people in the KSA opt to purchase personal insurance to evade these challenges faced in public healthcare provision. Therefore, there is growing need for an extended medical insurance scheme to smoothen the efficiency of service provision through lifting the burden off of the Ministry of Health $(\mathrm{MOH}) .{ }^{15}$ By increasing access to services from private health facilities, health insurance could lead to a general improvement in the health standards of the population. However, such outcomes are dependent on health insurance nudging people into health-seeking behaviour, a topic whose empirical evidence remains sparse in Saudi. Therefore, this study aims to explore if health insurance prods healthseeking behaviour using data obtained from the KSA.
A notable concern when estimating the effects of insurance on health outcomes is the potential presence of adverse selection and moral hazard. ${ }^{16}$ In adverse selection health risky individuals would self-select into insurance, while moral hazard implies abuse of the medical scheme through over utilisation. ${ }^{17}$ A classical method to evade the influence of these behaviours is randomly allocating the insurance amongst the subjects, which is not possible for secondary data based studies. However, methods that exploit exogenous variations in covariates of interest could be used to obtain the causal effects of insurance. Therefore, this study uses instrumental variables in combination with inverse propensity weights to account for such possible potential endogeneity.

Our study on the topic remains relevant as the literature on health insurance has not yet covered health-seeking relating to medical check-ups, let alone those check-ups specific for chronic diseases. The context of KSA becomes a compelling case, because health insurance and its effects on health outcomes have not received adequate attention in the KSA - nor even in the entire Arabian Gulf region. These Arabian Gulf countries possess unusual characteristic and demographic challenges that make health-financing results from elsewhere non-generalizable to this region. ${ }^{18}$ For instance, an unusually high percentage of expatriate residents makes these countries unable to fit in to the World Bank classified category of low-income or high-income healthcare demand attributes. ${ }^{14,19}$ Furthermore, while low-income countries largely finance healthcare by international assistance and high-income countries by individual contributions for healthcare, through tax payment or social insurance payments, the Arabian Gulf countries finance healthcare mainly through revenues from natural resources. ${ }^{18}$ As such, generating estimates on the effects of health insurance on healthseeking behaviour that are specific to these countries remains key to provision of policy relevant advocacy.

\section{Healthcare Provision and the Health Insurance in Saudi Arabia}

The KSA provides free access to healthcare services through the $\mathrm{MOH}$ to both Saudis and non-Saudis working in the government sectors. Furthermore, the KSA provides free health services to the general public, which exorbitantly raises the cost of financing healthcare in the kingdom, exacerbated by the rapid population growth and increased prices of medical technology. ${ }^{15}$ Public health provision in Saudi is of high quality; however, it has faced efficiency challenges 
due to the overwhelmingly large number of people that it caters for. ${ }^{13}$ Besides, the Kingdom has always had over $80 \%$ of private sector employees as expatriates, accounting for $56 \%$ of the gross Saudi workforce, providing a further strain on the healthcare resource envelope. ${ }^{20}$ In response, the Saudi government enacted the Cooperative Health Insurance Law. The law aimed at reducing pressure from public health services through forcing private companies to internalize the healthcare expenditures of their expatriate employees, with a compulsory insurance paid by the employers to increase usage of private health facilities. ${ }^{14}$

Furthermore, the Saudi government established the Council of Cooperative Health Insurance (CCHI) to "regulate and supervise a health insurance strategy for the Saudi healthcare market". ${ }^{12}$ Amongst its mandates, the CCHI manages unified health insurance benefit packages determined by insurance law. By 2016, Saudi insured about 38\% of its population, out of which $78 \%$ were expatriates and the remaining were Saudi citizens in the private sector. All other citizen who have free access to the public health sector can use the private healthcare sector on a fee for services basis at the point of use or can purchase insurance using personal income. ${ }^{14,21}$ Despite this massive expansion, health insurance in the KSA remains in a development stage, aiming at reaching out to widespread national coverage. ${ }^{18}$ Empirical evidence reveals that individuals are willing to participate in the national contributory health insurance scheme, and that awareness about the range of services that insurance coverage provides is associated with increased utilization of those health services. $^{22,23}$

Nevertheless, no study in the KSA has investigated the effects of health insurance on preventive health through enhanced health-seeking behaviour. This study focuses on the influence of health insurance on attendance of medical check-ups, a component of preventive health, in the KSA. Preventive health seeking through medical check-up also becomes handy in the fight against the prevalence of noncommunicable diseases that are unprecedentedly claiming more lives in the new age of Saudi. ${ }^{24}$ Hence, this study further examines if insurance increases the chances of attending medical check-ups that are specific for noncommunicable diseases.

\section{Materials and Methods}

\section{Study Setting}

The study is conducted in the KSA, a country in Western Asia comprising the largest part of the Arabian Peninsula with a land area of approximately $2150000 \mathrm{~km}^{2}$. The KSA has one of the youngest populations with 16.3 million people under the age of 25, representing about $49 \%$ of the total population. ${ }^{25}$ World Bank Categorises KSA as a high income economy with a high Human Development Index. $^{26}$ The KSA also becomes one of the important Islamic heritage sites. The KSA is one of the largest oil producer and exporter and finances its economy, which includes healthcare service provision, using the natural resource. $^{27}$

\section{Database}

This paper used data from the Saudi Family Health Survey (FHS) conducted in 2018 by the General Authority for Statistics (GaStat). ${ }^{28}$ The FHS is a family field survey that falls under the classification of education and health statistics. The FHS collects information by visiting a representative sample of the population for all administrative regions in the KSA every 3 years. The Family Health Survey 2018 is the first collaborative stage between GaStat and a number of entities in the health sector in the Kingdom such as the Ministry of Health, the Saudi Health Council, as well as the private and academic sectors.

The Survey contains number of questions that obtain information among others, relating to the health status of community members and the chronic diseases suffered by these individuals. ${ }^{28}$ Within the health status section, the FHS asks individuals if they make periodic health checkups. A follow-up question further asks respondents about the type of medical check-up. We used these variables to capture health-seeking behaviour. Besides, the survey also captures general information on the household members, with a question on insurance coverage for the respondents, our variable of interest. A follow-up question asks about the kind of health insurance funder. Furthermore, the survey provides data on marriage, family planning, fertility and births, family income and expenditure, and the use of contraceptives for married females, in addition to indicators related to mortality and other household-level attributes. We used these sections to obtain the characteristics included in the paper as control variables.

\section{Data Cleaning and Management}

The FHS collected a total sample of 15.265 individuals randomly selected across all of the 13 regions of the Kingdom. The study conducted data cleaning and management in Stata statistical package of version 16.1. During 
the cleaning and management, the study excluded all individuals who had missing responses on insurance and medical check-up. The final sample with complete information that was used in estimations was from 8845 respondents.

\section{Measurements Outcome Variables}

The outcome variables in our analysis comprised attendance of medical check-ups in the year preceding the survey. We accounted for the following two measures. First, the probability of one attending any medical checkup (represented as a dummy, where medical check-up takes the value of 1 , and 0 for no medical check-up). Second, the probability of one attending four specific check-ups for cancer, cholesterol, blood pressure, and diabetes (all four are dummies with the value of 1 assigned to check-up, and 0 assigned to no check-up).

\section{Treatment Variables}

The treatment variables in this study comprised individuallevel coverage of health insurance accounted for by two measures. The first was a person holding health insurance irrespective of the kind of health insurance funder, and the second captured three kinds of insurance categorized as those paid by the government, the private sector, or out of personal income (both treatments are dummies, where the value of 1 represents those that were insured and 0 for those that were uninsured). The first can determine the homogenous effects of insurance, while the second whether different kinds of health insurance nudge the diverse effects on the outcome of interest.

\section{Conditioning Variables}

This paper included conditioning variables to free the analysis from bias due to omission of important insurancecorrelated determinants of medical check-ups. We specifically controlled for the age of the individuals and gender (another dummy variable where 1 captures male respondents and 0 represents female respondents). We also controlled for marital status (dummy variable where 1 identifies a married respondent, while 0 represents unmarried individuals, which includes the never married, the divorced and widows) and employment status (where 1 represents the employed and 0 the unemployed). To account for neighbourhood social economic status (SES), we included household income, disaggregated into five quintiles, ie, five income groups (from lowest to highest income), so that approximately $20 \%$ of the sample was in each group. Furthermore, the paper included subjective health captured by a dummy, where 1 refers to those who perceive themselves to have good health and 0 for those with bad self-assessed health. In the good health category, we included those who reported either good or very good health. The reference group was those who had bad health; this subgroup included those who reported to have mediocre, bad, or very bad health. To account for spatial variations in characteristics of the subjects, we included regional fixed effects.

\section{Empirical Strategy}

\section{Econometric Model}

The empirical application of our research question demands modelling health-seeking behaviour as a function of insurance. We follow Robyn, Fink, Sié, Sauerborn ${ }^{29}$ to estimate a linear parametrised function of insurance presented as follows:

$$
\text { Checkup }_{i}=\alpha_{1} \text { Insurance }_{i}+\alpha_{2} \text { Control }_{i}+\alpha_{3} \text { Region }_{j}+\mu_{i}
$$

Equation (1) captures the relationship between health insurance and health-seeking behaviour. We defined health-seeking behaviour as a dummy variable on whether an individual makes health check-up visits or not. If health insurance relates to increased probability of medical check-up, the coefficient of health insurance $\alpha_{1}$ becomes positive, and an alternative sign would mean that health insurance relates to the reduced probability of going for a medical check-up. In the equation, $\alpha_{2}$ represents the effects of a vector of control variables included in the estimations, $\alpha_{3}$ refers to the effects of regional fixed effects, and $\mu_{i}$ captures an idiosyncratic error term assumed to be independent and identically distributed.

Of notable concern when estimating the equation using ordinary least squares (OLS) is that insurance holders and non-holders may be systematically different in their characteristics, which would result in biased estimates. For instance, individuals of different ages or different levels of education and employment status may have different tastes for health-seeking behaviour in line with selfperceived opportunity costs of being sick, leading to an over- or under-estimation of the insurance effects. Moreover, Saudi mainly provides insurance to employed individuals through their employers. Insured people would therefore have a different health risk profile and hence dissimilar health-seeking behaviour relative to the uninsured. To account for these observed and unobserved 
heterogeneities, we employed matching and instrumental variables techniques.

\section{Propensity Score Matching}

Propensity score matching involves making the treatment and control groups comparable in the analysis regarding observable characteristics. In this paper, we generated the insurance participation predictions using a logit model, presented as follows:

$$
\text { Insurance }_{i}=\delta_{1} \text { Controls }_{i}+\delta_{2} \text { Region }_{j}+\nu_{i}
$$

Here, we regressed insurance on all the other control variables included in Equation (1), and $\nu_{i}$ represents an idiosyncratic error term (we presented the output for this prediction in the results section). We used the estimates from Equation (2) to generate the nearest neighbour propensity scores of participations in insurance, conditional on observable attributes. Following Karamba and Winters, ${ }^{30}$ we used the propensity scores to weight each observation in the treatment group by one, and those of the control group as a fraction of one subtracting the propensity score. We used the inverse of these propensity scores to weight all our estimations. The usage of the inverse weights shifts the distribution of controls to match the treatment characteristics. A further advantage of using the inverse weighting method is that is avoids the loss of any of the variables in the sample due to matching.

\section{Identification of Lewbel Instrumental Variables}

Instrumental variables (IVs) enable the identification of the effects of interest by accounting for unobservable heterogeneities. IVs achieve this objective by identifying exogenous covariates of the dependent variables that only work through the independent variable (health insurance, in our case). The technique rests on two assumptions. The first is that the instrument of choice should cause a significant change in the regressor (instrument relevance). Secondly, the instrument should be orthogonal to the residuals of the main equation (instrument validity). Instrument relevance can be empirically tested and verified. In our case, it demands that the relationship between the instruments and insurance should produce an F-statistic larger than 10. However, instrument validity cannot be empirically tested (we can only argue for validity with statistical and economic intuition). The challenge, therefore, is finding the instrument that meets the validity assumption. We did not have such variable in our dataset. Nevertheless, Lewbel ${ }^{31}$ provided a method of instrumental variables that attains identification, even in the absence of an instrument that meets the validity assumption.

The Lewbel approach can be described as follows (here, we describe the approach with reference to Equation (1)). Let:

$$
\begin{array}{ll}
Y_{1}=X^{\prime} \alpha_{1}+Y_{2} \delta_{1}+\mu_{1} & \mu_{1}=\beta_{1} U+V_{1} \\
Y_{2}=X^{\prime} \alpha_{2}+\mu_{2} & \mu_{2}=\beta_{2} U+V_{2}
\end{array}
$$

$Y_{1}$ captures medical check-up, $Y_{2}$ health insurance. We depict unobserved preferences across individuals as $U$ which includes individual risk aversion to poor health. We present error terms as $V_{1}$ and $V_{2}$ (assumed independent and identically distributed). Lewbel ${ }^{31}$ posited that taking a vector $R$ of observed variables, one can use $[R-E(R)] \mu_{2}$ as an instrument, provided that: first, we meet the standard instrumental variables assumptions that $E\left(X \mu_{1}\right)=0, E\left(X \mu_{2}\right)=0$ and $E\left(X X^{\prime}\right)$ are non-singular. Secondly, we should meet the additional assumptions that $\operatorname{cov}\left(R, \mu_{1}, \mu_{2}\right)=0$ and $\operatorname{cov}\left(R, \mu_{2}^{2}\right) \neq 0$. $R$ could be a subset of $X$ or all variables of $X$, in our case all control variables included in Equation 1.

Lewbel $^{31}$ further showed that not all of the required assumptions are unique to his method, except the last, which demands the presence of heteroscedasticity in the first stage of predicting the determinants on insurance. By construction, discreet dependent variable models such as that of insurance have heteroscedasticity. ${ }^{32}$ We attained identification by having insurance not correlated with the product of heteroskedastic errors. Lewbel ${ }^{31}$ developed the method using a continuous regressor. However, in his most recent work, he extended the previous method by showing that we can still get consistent estimates in the case of a binary endogenous independent variable. ${ }^{33}$ Therefore, we used the recent theoretical discovery ${ }^{31,33}$ in the instrumental variables' two-stage least squares technique to estimate a medical check-up Equation (1) without the use of external instruments.

\section{Empirical Findings}

Although our interest lies in estimating the relationship between health insurance and medical check-up, we first present the summary statistics for the variables used in the analysis. Thereafter, we validate our method, the propensity score matching, and provide covariate test results. After providing the validity of our matching, we present the main results, depicting the relationship between health insurance and medical check-up. The results that follow provide the output that 
accounts for both observed and unobserved endogeneity. Last, we provide robustness checks for our main findings.

\section{Sample Summary Statistics}

Table 1 provides the summary statistics of the variables used in the analysis, comparing the means of the insured (3163) against the uninsured (5682) individuals. Out of the 3163 insurance holders, 2768 obtain the insurance through their private sector employers, 235 through the government, and 160 pay for it from their own income. The insured attend medical check-ups more than the uninsured, and there exists a significant difference, particularly in the medical insurance concerning cholesterol. This provides preliminary evidence that insurance is associated with increased probability of attending a medical check-up. Notably, $40 \%$ of the insured are Saudi nationals, while $60 \%$ are non-Saudis. Conversely, amongst the non-insured, $90 \%$ are Saudi nationals and about $10 \%$ non-Saudi nationals. The rest of the table provides the control variables used in the analysis, and most of them are statistically different across the treatment and the control groups, which further justifies the need to use matching.

\section{Matching Results}

Table 2 presents the logit estimates used to predict the propensity scores. We observed that increased age, high subjective health, being male, married, educated, and residing in a relatively rich household are positively

Table I Summary Statistics of the Variables Used in the Analysis

\begin{tabular}{|l|l|l|l|}
\hline & Insured & Uninsured & Difference (t-test) \\
\hline Check-up & 0.617 & 0.539 & $0.078^{* * *}$ \\
Cancer check-up & 0.027 & 0.030 & -0.003 \\
Blood pressure check-up & 0.169 & 0.159 & 0.010 \\
Cholesterol check-up & 0.125 & 0.081 & $0.044^{* * *}$ \\
Diabetes check-up & 0.174 & 0.168 & 0.006 \\
Age & 40.945 & 44.460 & $-3.515^{* * *}$ \\
Subjective health & 0.896 & 0.798 & $0.098^{* * *}$ \\
Male & 0.650 & 0.463 & $0.187^{* * *}$ \\
Married & 0.819 & 0.759 & $0.060^{* * *}$ \\
Employed & 0.608 & 0.388 & $0.220^{* * *}$ \\
Educated & 0.975 & 0.893 & $0.082^{* * *}$ \\
Saudi national & 0.400 & 0.903 & $-0.503 * * *$ \\
Non-Saudi & 0.600 & 0.097 & $0.503^{* * *}$ \\
First income quintile & 0.183 & 0.227 & $0.044^{* * *}$ \\
Second income quintile & 0.227 & 0.174 & $-0.053^{* * *}$ \\
Third income quintile & 0.229 & 0.162 & $-0.067 * * *$ \\
Fourth income quintile & 0.213 & 0.206 & -0.006 \\
Fifth income quintile & 0.148 & 0.230 & $0.082^{* * *}$ \\
Observations & 3163 & 5682 & \\
\hline Note: & & &
\end{tabular}

Note: $* * * p<0.01$
Table 2 Logit, Participation in Health Insurance, Model

\begin{tabular}{|c|c|c|}
\hline & (I) & $95 \% \mathrm{Cl}$ \\
\hline & Insured & \\
\hline Age & $\begin{array}{l}0.007 * * * \\
(0.002)\end{array}$ & $0.003-0.012$ \\
\hline Subjective health & $\begin{array}{l}0.283 * * * \\
(0.092)\end{array}$ & $0.159-0.514$ \\
\hline Male & $\begin{array}{l}0.580 * * * \\
(0.077)\end{array}$ & $0.434-0.730$ \\
\hline Married & $\begin{array}{l}0.398 * * * \\
(0.077)\end{array}$ & $0.209-0.502$ \\
\hline Employed & $\begin{array}{l}-0.034 \\
(0.081)\end{array}$ & $-0.204-0.106$ \\
\hline Educated & $\begin{array}{l}\text { I.I72*** } \\
(0.161)\end{array}$ & $0.925-1.544$ \\
\hline Saudi national & $\begin{array}{l}-2.750 * * * \\
(0.070)\end{array}$ & -2.836 to -2.568 \\
\hline Second income quintile & $\begin{array}{l}0.231 * * * \\
(0.087)\end{array}$ & $0.092-0.440$ \\
\hline Third income quintile & $\begin{array}{l}0.344 * * * \\
(0.092)\end{array}$ & $0.18 I-0.537$ \\
\hline Fourth income quintile & $\begin{array}{l}-0.017 \\
(0.090)\end{array}$ & $-0.079-0.257$ \\
\hline Fifth income quintile & $\begin{array}{l}-0.20 I^{* *} \\
(0.089)\end{array}$ & -0.369 to -0.002 \\
\hline Regional fixed effects & Yes & \\
\hline Constant & $\begin{array}{l}-2.570 * * * \\
(0.303)\end{array}$ & -2.963 to -1.891 \\
\hline Observations & 8845 & \\
\hline
\end{tabular}

Notes: Robust standard errors in parentheses. ${ }^{* * *} p<0.01$, $* * p<0.05$. Cl captures confidence intervals.

associated with holding insurance. Saudi nationality negatively relates with holding insurance. This result underscores the fact that health insurance targeted the expatriate population from its onset in Saudi. We predicted insurance acquisition propensity scores from these estimates and plotted their distribution between the treated and control groups before and after matching, as shown in Figure 1.

Figure 1 shows the kernel density distribution of the propensity scores between the insured (treated) and the uninsured (untreated) groups. The left unweighted panel shows how the two comparison groups differ before matching, while the right weighted panel shows the output after matching. The unweighted figure shows that some observations were in the 

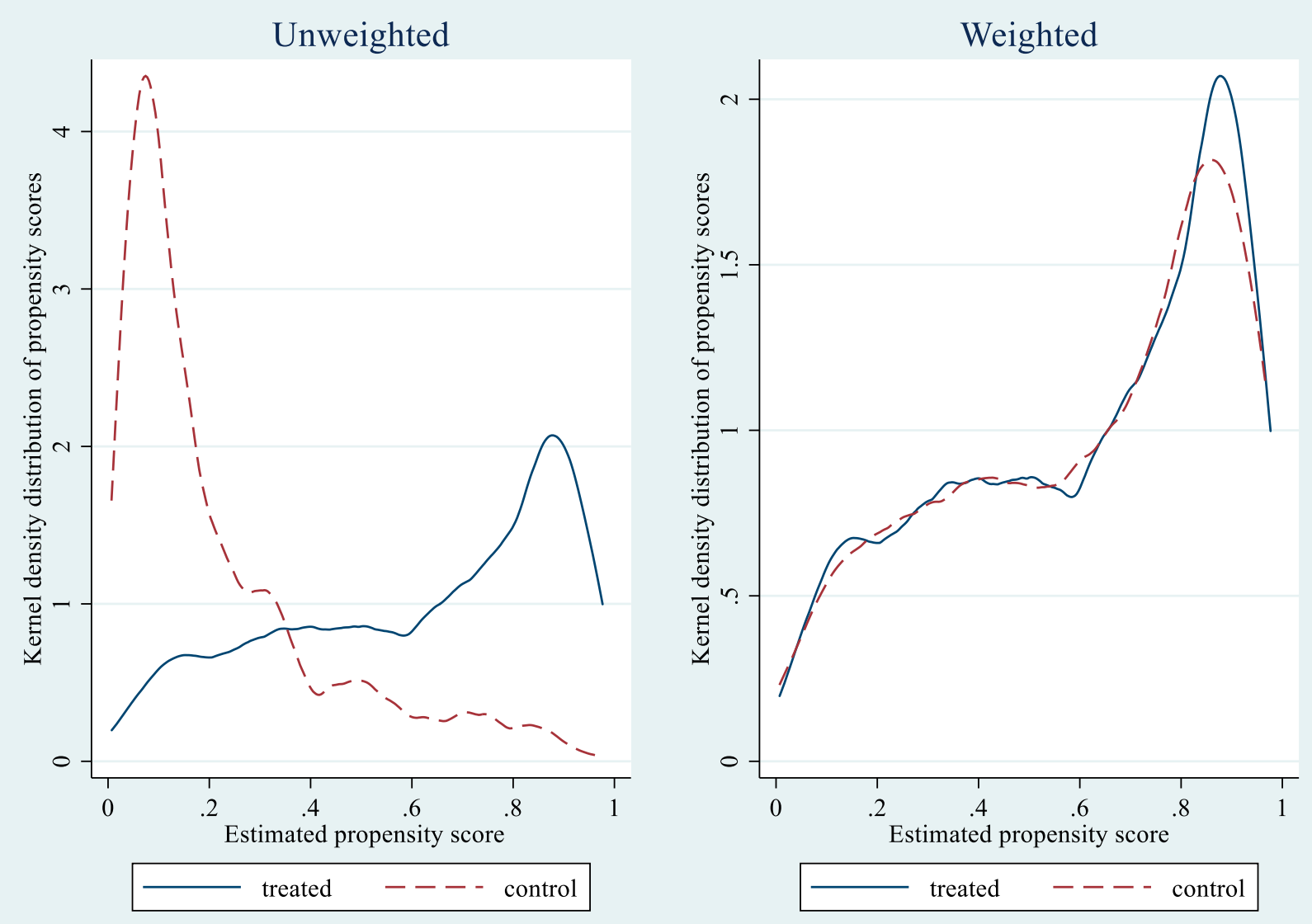

Figure I The kernel density distribution of propensity scores between the insured (treated) and the uninsured (untreated).

region of common support before matching, while the weighted figure show that the groups look more similar after matching. This provides evidence that running Equation (1) without propensity score matching would result in biased estimates.

In Table 3, we provide results of the formal test of covariates balance. The table reveals that without matching, the average propensity score is 0.216 , while after matching, it reduces to 0.062 . The log likelihood and chisquare $\mathrm{p}$-values reject the null hypothesis that the matched and unmatched covariates are statistically the same. This means that the treatment and control group covariates are different with and without matching. Column 4 of the table shows that the unmatched sample has a covariate bias of 20, while after matching, the bias reduces to 8.2. Similarly, the median bias reduces from 20.1 to 4.4 when the covariates are unmatched and matched, respectively.

Table 4 further examines the differences between the means of the treated and control groups before and after matching by presenting the Average Treatment Effects for the Treated (ATT). We see that after matching the differences are increased and they are statistically significant (T-stat $>2$ ). These findings confirm that matching can reduce bias in estimating the relationship between health insurance and health-seeking behaviour; hence the unmatched results could underestimate the effects of interest.

Table 3 Propensity Score Matching Test Results

\begin{tabular}{|l|l|l|l|l|l|}
\hline Sample & Propensity Score & LR Chi-Square & $\boldsymbol{p}>\mathbf{C h i}^{\mathbf{2}}$ & Mean Bias & Median Bias \\
\hline Unmatched & 0.216 & 2020.52 & 0.000 & 20.000 & 20.100 \\
Matched & 0.062 & 337.72 & 0.000 & 8.200 & 4.400 \\
\hline
\end{tabular}


Table 4 Mean Differences Between the Matched and Unmatched Samples

\begin{tabular}{|l|l|l|l|l|l|l|}
\hline Variable & Sample & Treated & Controls & Difference & S.E. & T-stat \\
\hline Check-up & Unmatched & 0.621 & 0.539 & 0.082 & 0.011 & 7.49 \\
& ATT & 0.621 & 0.266 & 0.355 & 0.030 & 11.8 \\
\hline
\end{tabular}

\section{Health Insurance and Health-Seeking Behaviour}

To understand the relationship between health insurance and health-seeking behaviour in the KSA, we regressed medical check-up on insurance, and the results are presented in Table 5. The results are an application of the linear probability-OLS model on a matched sample. Column 1 shows that having health insurance increases the probability of going for a medical check-up by about $17 \%$. This result confirms what we found in the summary statistics that insurance relates to increased chances of going for a medical check-up. The results could be due to either the insured being encouraged to maximize the value for the investment or that people go for a check-up because they are aware that the insurance company can pay for any discovered ailment.

In the context of the KSA, the health insurance scheme possesses unique attributes. Particularly, the establishment of the health insurance policy targeted private sector employees who are mostly expatriates. As such, it is worthwhile to understand if the observed role of insurance could differ in size between the locals and expatriates. Since government health facilities cover the locals free of charge, one would anticipate that insurance would have a larger effect on non-

Table 5 The Relationship Between Health Insurance and HealthSeeking Behavior

\begin{tabular}{|c|c|c|c|}
\hline Dependent Variables & (I) & (2) & (3) \\
\hline Medical check-up & Full sample & Saudi national & Non-Saudi \\
\hline Insured & $\begin{array}{l}0.168 * * * \\
(0.013) \\
0.136-0.202\end{array}$ & $\begin{array}{l}0.125 * * * \\
(0.014) \\
0.109-0.164\end{array}$ & $\begin{array}{l}0.195 * * * * \\
(0.032) \\
0.115-0.225\end{array}$ \\
\hline All controls & Yes & Yes & Yes \\
\hline Regional fixed effects & Yes & Yes & Yes \\
\hline Constant & $\begin{array}{l}0.192 * * * \\
(0.058) \\
0.114-0.394\end{array}$ & $\begin{array}{l}0.204^{* * *} \\
(0.066) \\
0.119-0.352\end{array}$ & $\begin{array}{l}0.064 \\
(0.113) \\
0.037-0.514\end{array}$ \\
\hline Observations & 8845 & 6394 & 2451 \\
\hline R-squared & 0.255 & 0.272 & 0.231 \\
\hline
\end{tabular}

Notes: Robust standard errors in parentheses. ${ }^{* * *} p<0.01$. All ranges in the third row of every variable estimates are the $95 \%$ confidence intervals.
Saudis relative to Saudis. Therefore, we partitioned the sample into Saudi nationals and non-Saudis. In Table 5, Column 2 provides the results for the Saudi nationals and column 3 presents the findings on the non-Saudi national sample.

The results showed that receiving health insurance increases the chances of attending a medical check-up by about $13 \%$ amongst Saudis while it enacts a $20 \%$ increase effect on non-Saudis. As non-Saudis were the initial target population of the insurance policy they possibly had a firstmover advantage of understanding the benefits and responded through increased utilization. Besides, non-Saudis do not have access to the free medical care that Saudis receive. Therefore, these expatriates would treat their curative health problems either by the insurance or, in the worst-case scenario, by out of pocket payments. These potential costs increase the incentives for preventive health amongst the nonSaudis through increased medical check-ups.

The results presented thus far account for the observable differences between the insured and the uninsured. Nevertheless, one would anticipate the existence of unobservable differences that may confound the relationship between insurance and medical check-ups, for instance, differences in risk aversion to poor health or variations in preferences for good health. We therefore attempted to validate these results with an additional method able to account for both observed and unobserved endogeneity.

\section{Endogeneity Concerns}

In this subsection, we present results that combine both the matched method and the Lewbel instrumental variables technique. In the Lewbel, the study used all of the controls in our equation to generate the internal instruments. Table 6 presents the model results. First, we validated that our generated instruments were relevant. We present the F-test statistics in row 5 and their critical values in row 6 for all the three models. For the full sample, the F-statistic is 240, above the critical value of 22. For the Saudi nationals' sample, the F-statistic is 439, well above the critical value 22. In the non-Saudi nationals' model, the F-statistic is 135, again above the critical value of 22 . Therefore, in all the three models, the results support that our instruments are strong, and therefore relevant for the analysis. 
Table 6 The Effects of Health Insurance on Health-Seeking Behavior

\begin{tabular}{|c|c|c|c|}
\hline & (I) & (2) & (3) \\
\hline & Full sample & Saudi national & Non-Saudi \\
\hline & check-up & check-up & check-up \\
\hline Insured & $\begin{array}{l}0.215^{* * * *} \\
(0.024) \\
0.103-0.183\end{array}$ & $\begin{array}{l}0.132^{* * *} \\
(0.022) \\
0.120-0.263\end{array}$ & $\begin{array}{l}0.292 \text { *** } \\
(0.051) \\
0.178-0.295\end{array}$ \\
\hline All controls & Yes & Yes & Yes \\
\hline Regional fixed effects & Yes & Yes & Yes \\
\hline Constant & $\begin{array}{l}0.156 * * * \\
(0.059) \\
0.084-0.354\end{array}$ & $\begin{array}{l}0.200^{* * *} \\
(0.067) \\
0.115-0.350\end{array}$ & $\begin{array}{l}-0.033 \\
(0.115) \\
0.026-0.495\end{array}$ \\
\hline $\begin{array}{l}\text { F-statistic } \\
5 \% \text { F-critical }\end{array}$ & $\begin{array}{l}240 \\
22\end{array}$ & $\begin{array}{l}439 \\
22\end{array}$ & $\begin{array}{l}135 \\
22\end{array}$ \\
\hline Observations & 8845 & 6394 & 2451 \\
\hline R-squared & 0.254 & 0.272 & 0.226 \\
\hline
\end{tabular}

Notes: Robust standard errors in parentheses. $* * * p<0.01$. All ranges in the third row of every variable estimates are the $95 \%$ confidence intervals.

Column 1 of Table 6 shows that overall insurance increases the probability of going for a medical checkup, and the effects are even higher here when we combine both methods relative to only using the matching. This reaffirms our earlier findings that insurance indeed leads to positive behaviour change toward more health seeking. Column 2 in this table also conforms to our earlier findings and column 3 confirms the previous result that insurance really matters, particularly amongst the non-Saudis. These findings endorse that what we initially observed in the main results in Table 5 is not out of random chance.

\section{Robustness Checks}

We performed a set of robustness checks on our initial results of the matched sample. We first examined the heterogeneity in the effects of insurance by breaking medical check-up into four categories. Thereafter, we examined the effects of insurance on medical check-up, conditional on who pays for the insurance. These estimations provide a detailed output that would help policymakers to target the right population and, at the same time, to have an idea on what to anticipate regarding specific behaviour change in medical check-ups due to health insurance.

Table 7 breaks down the types of medical check-ups. Column 1 shows that insurance marginally increases cancer check-ups. Columns $2-4$ show that insurance strongly increases the probability of one going for a blood pressure, cholesterol, or diabetes check-up. Considering that these three latter diseases are serious burdens in the kingdom, we can anticipate that people are becoming more aware of their dangers and, where possible, utilize insurance to prevent these ailments by constantly monitoring their health.

Microeconomics theory posits that willingness to pay for a commodity relates to the utility that an individual derives from the consumption of that particular good. Therefore, considering health insurance as a good procurement in the insurance market, those who pay for their own are more likely to utilize most of the provisions within the coverage

Table 7 The Relationship Between Health Insurance and Specific Medical Check-Ups

\begin{tabular}{|c|c|c|c|c|}
\hline & (I) & (2) & (3) & (4) \\
\hline & Cancer & Blood Pressure & Cholesterol & Diabetes \\
\hline Insured & $\begin{array}{l}0.009 * \\
(0.005) \\
0.008-0.034\end{array}$ & $\begin{array}{l}0.049 * * * \\
(0.013) \\
0.024-0.104\end{array}$ & $\begin{array}{l}0.051 * * * \\
(0.011) \\
0.003-0.070\end{array}$ & $\begin{array}{l}0.035^{* * *} \\
(0.013) \\
0.007-0.090\end{array}$ \\
\hline All controls & Yes & Yes & Yes & Yes \\
\hline Regional fixed effects & Yes & Yes & Yes & Yes \\
\hline Constant & $\begin{array}{l}0.022 * \\
(0.013) \\
-0.020-0.049\end{array}$ & $\begin{array}{l}0.025 \\
(0.060) \\
-0.086-0.158\end{array}$ & $\begin{array}{l}0.038 \\
(0.057) \\
-0.035-0.197\end{array}$ & $\begin{array}{l}0.022 \\
(0.061) \\
-0.096-0.153\end{array}$ \\
\hline Observations & 8845 & 8845 & 8845 & 8845 \\
\hline R-squared & 0.040 & 0.055 & 0.051 & 0.055 \\
\hline
\end{tabular}

Notes: Robust standard errors in parentheses. ${ }^{* * *} p<0.01,{ }^{*} p<0.1$. All ranges in the third row of every variable estimates are the $95 \%$ confidence intervals. 
Table 8 The Relationship Between Health Insurance and Health Seeking by Kind of Insurance

\begin{tabular}{|c|c|c|c|}
\hline & (1) & (2) & (3) \\
\hline & Full sample & Saudi nationals & Non-Saudi \\
\hline & check-up & check-up & check-up \\
\hline Government insurance & $\begin{array}{l}0.139 * * * \\
(0.028) \\
0.066-0.210\end{array}$ & $\begin{array}{l}0.096 * * * \\
(0.030) \\
0.051-0.168\end{array}$ & $\begin{array}{l}0.187 * * \\
(0.081) \\
-0.129-0.242\end{array}$ \\
\hline Private insurance & $\begin{array}{l}0.168^{* * *} \\
(0.013) \\
0.178-0.286\end{array}$ & $\begin{array}{l}0.125^{* * *} \\
(0.015) \\
0.086-0.166\end{array}$ & $\begin{array}{l}0.187^{* * *} \\
(0.033) \\
0.097-0.231\end{array}$ \\
\hline Personal insurance & $\begin{array}{l}0.217^{* * *} \\
(0.039) \\
0.149-0.320\end{array}$ & $\begin{array}{l}0.253^{* * * *} \\
(0.057) \\
0.120-0.355\end{array}$ & $\begin{array}{l}0.262^{* * *} \\
(0.059) \\
0.261-0.515\end{array}$ \\
\hline All controls & Yes & Yes & Yes \\
\hline Regional fixed effects & Yes & Yes & Yes \\
\hline Constant & $\begin{array}{l}0.179 * * * \\
(0.058) \\
0.085-0.361\end{array}$ & $\begin{array}{l}0.185^{* * *} \\
(0.066) \\
0.108-0.347\end{array}$ & $\begin{array}{l}0.050 \\
(0.112) \\
0.013-0.481\end{array}$ \\
\hline Observations & 8845 & 6394 & 2451 \\
\hline R-squared & 0.256 & 0.274 & 0.232 \\
\hline
\end{tabular}

Notes: Robust standard errors in parentheses. ${ }^{* * *} p<0.01$, **p $<0.05$. All ranges in the third row of every variable estimates are the $95 \%$ confidence intervals.

of the health insurance policy, such as medical check-ups. Therefore, generalizing that insurance leads to increased chances of medical check-ups would ignore the insurance parameter heterogeneity. We checked this by breaking down the insurance by the funder as presented in Table 8 .

Column 1 in Table 8 shows the full sample results. People who pay the insurance using their own money utilize it more, with a $22 \%$ increase in the chance of going for a medical check-up. Those paid by the private sector come second, with a $17 \%$ increase in the chance of going for a medical checkup. Finally, government-funded insurance leads to an increase in the probability of going for a medical check-up by $14 \%$. Columns 2 and 3 disaggregate the sample between nationals and non-nationals. The results from these last two columns conform to our earlier findings that insurance has a higher medical check-up effect amongst non-Saudis relative to Saudis.

\section{Discussion}

This study estimated the effects of health insurance on health-seeking behaviour using a national data from the KSA. The study employed propensity score matching to account for bias in observable characteristics of the respondents and instrumental variables to allow identification of the effects of interest while controlling for unobservable attributes. The study found that health insurance leads to an increased probability of going for medical check-up visits across all specifications. These results have important policy implications.

Firstly, by increasing chances of going for a medical check-up, health insurance has the potential to save costs on curative health. This result is in tandem with previous studies on the effects of insurance in reducing medical cost treatment. The literature showed that health insurance lower inpatient and outpatient treatment costs and reduces illness. ${ }^{34}$ This is the case because some health conditions, if not discovered or monitored through medical check-ups, can only become visible when they become worse, demanding more resources to treat. This could burden both the beneficiaries, if the latter problem is paid out of pocket, and the government in general, as the resources used could have been invested into other productive initiatives in the absence of this negative and delicate health condition. $^{35}$

Secondly, by increasing check-ups for both Saudis and non-Saudis, insurance can be effective in encouraging health-seeking even amongst Saudis, who have the privilege of using free public health facilities and could choose not to use the private health facilities. ${ }^{12}$ Studies examining healthseeking behaviour found the gender differentials that alienate female's health seeking tendency in male dominated areas. ${ }^{36}$ Females are less likely, to seek medical care despite having access to free health services as is the case in KSA. ${ }^{37}$ In Pakistan setting, the barriers to health-seeking include poor geographical access and cultural beliefs. ${ }^{36}$ Consequently, extending insurance, even to more Saudis across various geographical setting and gender, would yield improved preventive health outcomes for the kingdom at large. ${ }^{38}$ In addition, the results that non-Saudis use most of the insurance by having a high probability for check-ups relative to Saudis indicate that insurance is achieving its primary objective that was envisioned when the 1999 Insurance Act was being drafted. ${ }^{14}$ Arguably, this is a signal that insurance has indeed assisted in lifting off some of pressure from public health facilities to private providers. ${ }^{15}$

Thirdly, by increasing medical check-ups, particularly for blood pressure, cholesterol, and diabetes, health insurance plays a crucial role in managing the conditions of people living with these diseases that also happen to be lethal in the KSA. ${ }^{39-42}$ This finding is supported by evidence found in the 
United States of America (USA). In the USA insurance increases utilisation of medical services amongst those with chronic health conditions. ${ }^{43}$ Recent finding substantiates this evidence that insurance reduces mortality due to cancer and other chronic diseases in the same country. ${ }^{8}$ Therefore, wellmanaged health conditions should prevent the patients from becoming delicate to the extent of disrupting their productive labour market activities. ${ }^{44,45}$ However, care should be exercised as previous findings reveal that insurance could increase employment participation amongst permanent workers while reducing that of part-time employees. ${ }^{46}$

Finally, we have shown that the insurance effects on health seeking are higher when one pays for their own relative to those paid by the private or government sectors. In private insurance seek to extract maximum value for their money. ${ }^{47}$ As such, making personal paid insurance affordable has the highest potential for improving the general health of the KSA. However, subsidising private insurance should account for the potential inequality in health outcomes. For instance, in Korea, private insurance increases inequity in healthcare access that favours the rich. ${ }^{48}$ Furthermore, it is shown that individuals with health insurance funded by private sector employers are more likely to attend medical check-ups relative to those funded by the government. This reflects that over-reliance on free public health services, which is characteristic of most Saudi citizens shown by previous findings in the $\mathrm{KSA}^{18}$

The results established by this study reveal that health insurance leads to increased health-seeking behaviour through medical check-up. However, the potential magnitude of the insurance could be underestimated as supported by previous evidence on the behaviour of health seekers. For instance, in United Arab Emirates, culture and lack of knowledge on the services that the health system provides reduces health seeking, ${ }^{37}$ a result supporting earlier evidence from Qatar. ${ }^{49}$ Besides, health-seeking improves with rise in healthcare quality and availability of insurance in Iran. ${ }^{50}$ In addition, cultural beliefs and physical accessibility also affects health-seeking in Punjab. ${ }^{36}$ These attributes could also be undermining the effects of health insurance. Therefore, addressing similar health-seeking bottlenecks, could uncover larger effects of insurance on health-seeking in the KSA.

\section{Conclusions}

Our study has established that health insurance can be an appropriate tool in increasing health-seeking behaviour.
This conclusion calls for policy to leverage on the observed outcomes. Thus, increasing access to health insurance amongst the under-insured should be the primary goal of improving the general health status of people through the anticipated increase in medical check-ups. Therefore, a holistic approach that finances medical cover (health insurance) while accounting for the differences in behavior response to the financing mechanism of the insurance could greatly improve the general health of the Saudi population. Furthermore, policy should consider extending the health insurance to all Saudis, as the findings indicate that health insurance has the potential to reduce the incidence and to regulate the prevalence of chronic diseases such as hypertension, cholesterol, and diabetes through an increase in medical check-ups for these chronic ailments.

\section{Study Limitations}

Several limitations should be mentioned. First, the variables of interest (medical check-up and insurance) had some missing values. Therefore, further research should consider using panel datasets that can test whether attrition is correlated to results or not. Secondly, countries in the Arabian Gulf, including Saudi Arabia, have a unique type of financing where health expenditures are paid through natural resources. Therefore, results beyond the Arabian Gulf region should be used to verify the effects of insurance on health-seeking in different contexts. Lastly, this study's focus limited to using robust methods to expound the relationship between insurance on health-seeking in KSA. Future research should also consider directly estimating the effects of adverse selection and moral hazard on the estimates of insurance studies like these in the KSA.

\section{Data Sharing Statement}

The datasets generated and/or analysed during the current study are not publicly available due to privacy, confidentiality, and other restrictions. Access to data can be gained through the General Authority for Statistics in Saudi Arabia.

\section{Ethical Approval}

This paper does not require ethical approval because we used a secondary data. Furthermore, the data is deidentified. The outcomes of the analysis does not allow reidentification and the use of data cannot result in any damage or distress. 


\section{Acknowledgments}

This project was funded by the Deanship of Scientific Research (DSR) at King Abdulaziz University, Jeddah, under grant number D-666-120-1441. The authors, therefore, acknowledge, with thanks, the DSR for its technical and financial support.

\section{Author Contributions}

All authors made substantial contributions to conception and design, acquisition of data, or analysis and interpretation of data; took part in drafting the article or revising it critically for important intellectual content; gave final approval of the version to be published; and agree to be accountable for all aspects of the work.

\section{Funding}

This research was funded by the Deanship of Scientific Research (DSR) at King Abdulaziz University, grant number D-666-120-1441. The funders had no role in study design, data collection and analysis, decision to publish, or preparation of the manuscript.

\section{Disclosure}

The authors declare no conflict of interest.

\section{References}

1. UN. United Nations: Transforming our World: the 2030 Agenda for Sustainable Development. https://sustainabledevelopment.un.org/con tent/documents $/ 21252030 \% 20$ Agenda $\% 20$ for $\% 20$ Sustainable $\%$ 20Development\%20web.pdf. Published 2015. Accessed 2 Feb, 2020.

2. Levine D, Polimeni R, Ramage I. Insuring health or insuring wealth? An experimental evaluation of health insurance in rural Cambodia. J Dev Econ. 2016;119:1-15. doi:10.1016/j.jdeveco.2015.10.008

3. Sparrow R, Suryahadi A, Widyanti W. Social health insurance for the poor: targeting and impact of Indonesia's Askeskin programme. Soc Sci Med. 2013;96:264-271. doi:10.1016/j.socscimed.2012.09.043

4. Cuong NV, Linh VH. The impact of migration and remittances on household welfare: evidence from Vietnam. $J$ Int Migration Integr. 2018;19(4):945-963. doi:10.1007/s12134-018-0571-3

5. Raza WA, Van de Poel E, Bedi A, Rutten F. Impact of Communitybased Health Insurance on Access and Financial Protection: evidence from Three Randomized Control Trials in Rural India. Health Econ. 2016;25(6):675-687. doi:10.1002/hec.3307

6. Sheth K. Evaluating health-seeking behaviour, utilization of care, and health risk: evidence from a community based insurance model in India. Health Econ. 2013;66(12):246-267.

7. Hendriks ME, Wit FW, Akande TM, et al. Effect of health insurance and facility quality improvement on blood pressure in adults with hypertension in Nigeria: a population-based study. JAMA Intern Med. 2014;174(4):555-563. doi:10.1001/jamainternmed.2013.14458

8. Bittoni MA, Wexler R, Spees CK, Clinton SK, Taylor CA. Lack of private health insurance is associated with higher mortality from cancer and other chronic diseases, poor diet quality, and inflammatory biomarkers in the United States. Prev Med. 2015;81:420-426. doi:10.1016/j.ypmed.2015.09.016
9. Yang H, Huang X, Zhou Z, et al. Determinants of initial utilization of community healthcare services among patients with major non-communicable chronic diseases in South China. PLoS One. 2014;9:12. doi:10.1371/journal.pone.0116051

10. Rivera-Hernandez M, Rahman M, Mor V, Galarraga O. The impact of social health insurance on diabetes and hypertension process indicators among older adults in Mexico. Health Serv Res. 2016;51 (4):1323-1346. doi:10.1111/1475-6773.12404

11. Camacho A, Conover E. Effects of subsidized health insurance on newborn health in a developing country. Econ Dev Cult Change. 2013;61(3):633-658. doi:10.1086/669263

12. Walston S, Al-Harbi Y, Al-Omar B. The changing face of healthcare in Saudi Arabia. Ann Saudi Med. 2008;28(4):243-250. doi:10.5144/ 0256-4947.2008.243

13. Al-Harajin RS, Al-Subaie SA, Elzubair AG. The association between waiting time and patient satisfaction in outpatient clinics: findings from a tertiary care hospital in Saudi Arabia. J Family Community Med. 2019;26(1):17. doi:10.4103/jfcm.JFCM_14_18

14. Al-Hanawi MK, Alsharqi O, Almazrou S, Vaidya K. Healthcare finance in the Kingdom of Saudi Arabia: a qualitative study of householders' attitudes. Appl Health Econ Health Policy. 2018;16 (1):55-64. doi:10.1007/s40258-017-0353-7

15. Almalki M, FitzGerald G, Clark M. Health care system in Saudi Arabia: an overview. East Mediterr Health J. 2011;17(10):784-793. doi: $10.26719 / 2011.17 .10 .784$

16. Boone J. Basic versus supplementary health insurance: moral hazard and adverse selection. J Public Econ. 2015;128:50-58. doi:10.1016/j. jpubeco.2015.05.009

17. Haddad GK, Anbaji MZ. Analysis of adverse selection and moral hazard in the health insurance market of Iran. The Geneva Papers on Risk and Insurance-Issues and Practice. 2010;35(4):581-599. doi:10.1057/gpp.2010.20

18. Alkhamis A, Hassan A, Cosgrove P. Financing healthcare in Gulf Cooperation Council countries: a focus on Saudi Arabia. Int J Health Plann Manage. 2014;29(1):e64-e82. doi:10.1002/hpm.2213

19. Shah NM. The Management of Irregular Migration and Its Consequence for Development: Gulf Cooperation Council. International Labour Organization; 2009.

20. Alkhamis AA. The association between insured male expatriates' knowledge of health insurance benefits and lack of access to health care in Saudi Arabia. BMC Public Health. 2018;18(1):354. doi:10.1186/s12889-018-5293-0

21. CCHI. Council of Cooperative Health Insurance: annual Report of 2016. https://www.cchi.gov.sa/en/Studies/AnnualReport/Pages/ default.aspx. Published 2017. Accessed 5 March, 2020.

22. Al-Hanawi MK, Vaidya K, Alsharqi O, Onwujekwe O. Investigating the willingness to pay for a contributory National Health Insurance Scheme in Saudi Arabia: a cross-sectional stated preference approach. Appl Health Econ Health Policy. 2018;16(2):259-271. doi:10.1007/s40258-017-0366-2

23. Onwujekwe O, Onoka C, Uzochukwu B, Okoli C, Obikeze E, Eze S. Is community-based health insurance an equitable strategy for paying for healthcare? Experiences from southeast Nigeria. Health Policy. 2009;92(1):96-102. doi:10.1016/j.healthpol.2009.02.007

24. Algabbani A, Alqahtani A, BinDhim N. Prevalence and determinants of non-communicable diseases in Saudi Arabia. Food Drug Regul Sci J. 2019;2(2):1-10.

25. GASTAT. The General Authority for Statistics. https://www.stats.gov. sa/en. Published 2020. Accessed 29 May 2020.

26. Haque MI, Khan MR. Role of oil production and government expenditure in improving human development index: evidence from Saudi Arabia. Int J Energy Econ Policy. 2019;9(2):251.

27. Matar W, Anwer M. Jointly reforming the prices of industrial fuels and residential electricity in Saudi Arabia. Energy Policy. 2017;109:747-756. doi:10.1016/j.enpol.2017.07.060 
28. GASTAT. The General Authority for Statistics: family Health Survey https://www.stats.gov.sa/en/965. Published 2018. Accessed 15 January 2020.

29. Robyn PJ, Fink G, Sié A, Sauerborn R. Health insurance and health-seeking behavior: evidence from a randomized community-based insurance rollout in rural Burkina Faso. Soc Sci Med. 2012;75(4):595-603. doi:10.1016/j.socscimed.2011.12.018

30. Karamba RW, Winters PC. Gender and agricultural productivity: implications of the Farm Input Subsidy Program in Malawi. Agric Econ. 2015;46(3):357-374. doi:10.1111/agec.12169

31. Lewbel A. Using heteroscedasticity to identify and estimate mismeasured and endogenous regressor models. J Business Econ Stat 2012;30(1):67-80. doi:10.1080/07350015.2012.643126

32. Cameron AC, Trivedi PK. Microeconometrics: Methods and Applications. Cambridge university press; 2005.

33. Lewbel A. Identification and estimation using heteroscedasticity without instruments: the binary endogenous regressor case. Econ Lett. 2018;165:10-12. doi:10.1016/j.econlet.2018.01.003

34. Nguyen KT, Khuat OTH, Ma S, Pham DC, Khuat GTH, Ruger JP. Impact of health insurance on health care treatment and cost in Vietnam: a health capability approach to financial protection. $\mathrm{Am}$ J Public Health. 2012;102(8):1450-1461. doi:10.2105/AJPH.2011. 300618

35. Zeng W, Lannes L, Mutasa R. Utilization of health care and burden of out-of-pocket health expenditure in Zimbabwe: results from a national household survey. Health Syst Reform. 2018;4 (4):300-312. doi:10.1080/23288604.2018.1513264

36. Hussain R, Rashidian A, Hafeez A, Mirzaee N. Factors influencing healthcare seeking behaviour at primary healthcare level, in Pakistan. J Ayub Med College Abbottabad. 2019;31(2):201-206.

37. Hammad FT, Elbiss HM, Osman N. The degree of bother and healthcare seeking behaviour in women with symptoms of pelvic organ prolapse from a developing gulf country. BMC Women's Health. 2018;18(1):77. doi:10.1186/s12905-018-0570-8

38. Al-Hanawi MK, Alsharqi O, Vaidya K. Willingness to pay for improved public health care services in Saudi Arabia: a contingent valuation study among heads of Saudi households. Health Econ Policy Law. 2020;15(1):72-93. doi:10.1017/S17 44133118000191
39. Al-Hanawi MK, Chirwa GC, Kamninga TM. Decomposition of Gender Differences in Body Mass Index in Saudi Arabia using Unconditional Quantile Regression: analysis of National-Level Survey Data. Int J Environ Res Public Health. 2020;17(7):2330. doi:10.3390/ijerph17072330

40. Al-Hanawi MK, Chirwa GC, Pulok MH. Socio-economic inequalities in diabetes prevalence in the Kingdom of Saudi Arabia. Int $J$ Health Plann Manage. 2020;35(1):233-246. doi:10.1002/hpm.2899

41. El Bcheraoui C, Basulaiman M, Tuffaha M, et al. Status of the diabetes epidemic in the Kingdom of Saudi Arabia, 2013. Int J Public Health. 2014;59(6):1011-1021. doi:10.1007/s00038-014-0612-4

42. El Bcheraoui C, Memish ZA, Tuffaha M, et al. Hypertension and its associated risk factors in the Kingdom of Saudi Arabia, 2013: a national survey. Int J Hypertens. 2014;2014:564679. doi:10.1155/2014/564679

43. Davidoff A, Kenney G, Dubay L. Effects of the State Children's Health Insurance Program expansions on children with chronic health conditions. Pediatrics. 2005;116(1):e34-e42. doi:10.1542/peds.2004-2297

44. Zucchelli E, Jones AM, Rice N, Harris A. The effects of health shocks on labour market exits: evidence from the HILDA survey. Aust J Labour Econ. 2010;13(2):191.

45. O'Brien E. Employers' benefits from workers' health insurance. Milbank Q. 2003;81(1):5-43. doi:10.1111/1468-0009.00037

46. Page TF. Labor supply responses to government subsidized health insurance: evidence from kidney transplant patients. Int $J$ Health Care Finance Econ. 2011;11(2):133. doi:10.1007/s10754-011-9092-8

47. Jütting JP. Do community-based health insurance schemes improve poor people's access to health care? Evidence from rural Senegal. World Dev. 2004;32(2):273-288. doi:10.1016/j.worlddev.2003.10.001

48. Sohn M, Jung M. Effects of public and private health insurance on medical service utilization in the National Health Insurance System: national panel study in the Republic of Korea. BMC Health Serv Res. 2016;16(1):503. doi:10.1186/s12913-016-1746-2

49. Saleh N, Bener A, Khenyab N, Al-Mansori Z, Al Muraikhi A. Prevalence, awareness and determinants of health care-seeking behaviour for urinary incontinence in Qatari women: a neglected problem? Maturitas. 2005;50(1):58-65. doi:10.1016/j.maturitas.2004.04.003

50. Khajeh A, Vardanjani HM, Salehi A, Rahmani N, Delavari S. Healthcare-seeking behavior and its relating factors in South of Iran. J Educ Health Promot. 2019;8:183. Published 2019 Sep 30. doi:10.4103/jehp.jehp_93_19
Risk Management and Healthcare Policy

\section{Publish your work in this journal}

Risk Management and Healthcare Policy is an international, peerreviewed, open access journal focusing on all aspects of public health, policy, and preventative measures to promote good health and improve morbidity and mortality in the population. The journal welcomes submitted papers covering original research, basic science, clinical \& epidemiological studies, reviews and evaluations, guidelines, expert opinion and commentary, case reports and extended reports. The manuscript management system is completely online and includes a very quick and fair peer-review system, which is all easy to use. Visit http://www.dovepress.com/testimonials.php to read real quotes from published authors. 